\title{
Relações de trabalho e transporte na pesca de bagres no rio Solimões - AM
}

André de Oliveira Moraes - Geógrafo, mestre em Ciências do Ambiente e Sustentabilidade na Amazônia, pela Universidade Federal do Amazonas - UFAM. Pesquisador do Núcleo de Estudos e Pesquisas das Cidades na Amazônia Brasileira - NEPECAB/UFAM. E-mail: and.moraes@gmail.com

Tatiana Schor - Economista, doutora em Ciência Ambiental, pela Universidade de São Paulo - USP. Professora do Departamento de Geografia da UFAM e pesquisadora do Núcleo de Estudos e Pesquisas das Cidades na Amazônia Brasileira - NEPECAB/UFAM. E-mail: tatiana.schor@gmail. com

José Antônio Alves-Gomes - Oceanógrafo, Doutor em Biologia Marinha pela University of California, San Diego - Scripps Institution of Oceanography, UCSD - SIO. Pesquisador do Laboratório de Fisiologia Comportamental e Evolução - LFCE do Instituto Nacional de Pesquisas da Amazônia - INPA. E-mail: puraque44@gmail.com

\section{Resumo}

A pesca na Amazônia é uma atividade que tem permitido, ao longo dos anos, a reprodução da população ribeirinha, cuja dieta tem o peixe como item principal, coisa bastante comum nas comunidades e cidades do estado do Amazonas. Apesar de ainda ser praticada, a pesca de subsistência vem sendo substituída por uma pesca comercial, com os pescadores artesanais voltando-se para a atividade com a motivação de produzir valor de troca. Isso fica evidente na pesca de bagres, peixe que, por não ser consumido pela população das cidades do Solimões por causa de tabus alimentares, têm sido destinado à exportação. Entretanto, a alta perecibilidade do pescado conjugada à falta de infraestrutura adequada para a estocagem são fatores que sujeitam o pescador aos donos de frigoríficos. Com isso, as relações de trabalho são dotadas de complexas configurações cuja análise é o objetivo deste artigo.

\section{Palavras-chave}

Pesca na Amazônia. Bagres. Transporte. Relações de trabalho.

\begin{abstract}
Fishing in the Amazon basin characterizes itself as an activity that permited the reproduction of the riverine populations whose diet counted on the fish as its main sorce of protein, and is still understood as such in many communities of the Amazonas State, Brazil. Eventhough the artisanal subsistance fishery still exists it has been substituted by a comercial fishery where artisal fishers have turn towards the activity in order to generate exchange value. This fact is evident in the fishing of catfishes, that due to the fact that they are not consumed locally along the cities in the Solimões river due alimentary tabus, are becoming an important source of income to local populations. Catfish fishing has been an important export product in the region. The high perishablility of the fishes and the lack of infraestructure for stocking subjects the small fishermen to the owners of the refrigerated boats and comercial houses. The labour relations are organized in a complex structure of which this article with present and discuss.
\end{abstract}

\section{Keywords}

Fisheries in the Amazon. Catfishes. Transport. Labor relations. 


\section{INTRODUÇÃO}

O peixe tem sido objeto de especial atenção nas pesquisas feitas na Amazônia. Entretanto, segundo Welcomme, "estudos detalhados sobre a economia e o funcionamento da pesca nos rios tropicais são raros e a melhora na compreensão desses complexos sistemas sociais e ecológicos é de extrema importância" (WELCOMME, 2006, p. 11). A complexidade que envolve os estudos acerca da economia da pesca na Amazônia fica evidente quando se consideram os valores que o peixe pode assumir tanto como produto de consumo quanto como mercadoria. Nesse contexto, as relações de trabalho que se estabelecem na pesca também representam meandros de difícil apreensão. Elas variam no tempo (com a inserção de novas tecnologias como apetrechos de pesca, principalmente) e no espaço (considerando os diversos lugares com dinâmicas geossistêmicas e comerciais distintas) amazônico, e evidenciam um modo de produção capitalista quando são examinadas a cadeia produtiva da pesca e as relações comerciais entre os agentes dessa estrutura de mercado.

De modo geral, a demanda pelo peixe sempre esteve relacionada à alimentação local. Entretanto, Cruz (2007) afirma que a pesca no rio Solimões se intensificou devido à procura de bagres pelos grandes frigoríficos que estocam o pescado para exportação, sendo que esta espécie perfaz "cerca de 95\% da pescaria existente hoje na Amazônia brasileira, colombiana, peruana, boliviana e venezuelana" (BATISTA et al., 2005, p. 123). A situação dos bagres (popularmente conhecidos como "peixes lisos" ou "de couro") no que concerne à relação entre os pescadores e os demais agentes da cadeia produtiva apresenta outra lógica quando comparada à do peixe de escama. O tabu alimentar em torno do seu consumo entre a população amazonense (BARTHEM et al., 1997) faz com que apenas uma pequena parte desses peixes, geralmente surubins, siga para o comércio local, enquanto a maior parte é destinada à exportação, situação que configura uma estrutura de mercado mais complexa.

Este artigo apresenta uma discussão acerca da pesca com base em dados sobre a estrutura do mercado de peixes de escama (jaraqui, pacu, curimatã, pirarucu, tambaqui e matrinchã) e bagres (dourada, piramutaba e piraíba), obtidos nas cidades de Tabatinga, Benjamim Constant, São Paulo de Olivença, Amaturá, Santo Antônio do Içá, Jutaí, Tonantins, Fonte Boa, Uarini, Alvarães e Tefé, os quais compõem a calha do Rio Solimões. Essas cidades foram visitadas nos anos de 2007 e 2008 em períodos que compreendessem a enchente e a vazante do rio. Os dados foram coletados por meio de entrevistas com trabalhadores de frigoríficos e mercados municipais, principalmente, e ainda com membros de associações de pescadores e de compradores e vendedores de peixe.

\section{A "MERCADORIA-PEIXE"}

No estado do Amazonas, a situação do pescado envolve diversos aspectos desde os relacionados ao cotidiano alimentar da população regional até as diferenciadas relações de mercado que extrapolam o local, levando à adoção de novas lógicas na divisão territorial do trabalho, principalmente quando se trata de bagres.

Uma consideração importante a ser feita é a condição do peixe como mercadoria. Segundo Marx (1985, p. 45), "a utilidade de uma coisa faz dela valor de uso", sendo que "o valor de uso realiza-se somente no uso ou no consumo" (MARX, op. cit., p. 46). Por outro lado, as coisas também possuem uma propriedade intrínseca que as faz permutáveis por outras e "o que há de comum, que se revela na relação de troca ou valor de troca da mercadoria, é, portanto, seu valor" (MARX, op. cit., p. 47). Assim, a pesca apresenta outra perspectiva de mercado, abrangendo uma diferenciação na raiz das relações capitalistas de produção que é a discussão do valor de uso e valor de troca.

O peixe pode ser visto ainda como algo que não é necessariamente caracterizado por relações de mercado, mas cuja função no abastecimento alimentar da população urbana é cumprida. Isso ocorre porque

[...] uma coisa pode ser valor de uso, sem ser valor de troca. É esse o caso, quando sua utilidade para o homem não é mediada pelo trabalho. [...] Quem com seu produto satisfaz sua própria necessidade cria valor de uso mas não mercadoria.

[...] Para tornar-se mercadoria, é necessário que o produto seja transferido a quem

vai servir como valor de uso por meio da troca (MARX, 1985, p. 49).

Essa particularidade do pescado no Amazonas representa uma forma diferenciada de suprir as demandas de abastecimento. A condição de ser apenas valor de uso reflete as relações sociais que continuam a caracterizar o ribeirinho como um sujeito social, ainda não totalmente inserido nas relações capitalistas de produção.

Neste trabalho, analisa-se o peixe como mercadoria, constituído de valor de uso e valor de troca. Esse status, em que o trabalho é a propriedade que determina 
o valor das mercadorias, evidencia uma organização das forças de trabalho em torno de uma estrutura de mercado que viabilizará, da forma capitalista, a comercialização do peixe.

\section{A TIPOLOGIA COMERCIAL DE PEIXES NO AMAZONAS}

No rio Solimões, a pesca apresenta-se diversificada em função de algumas variáveis determinantes para a compreensão da atividade, principalmente no estado do Amazonas. O fato de haver diferentes espécies de peixes é o fator de maior influência na determinação das várias formas pelas quais as relações de trabalho serão definidas. Esse fator leva em conta questões biogeográficas, econômicas e culturais, cujo nível de articulação redundará em uma maior ou menor complexidade da estrutura de mercado presente na pesca, com reflexos diretos e indiretos na relação entre pescadores e atravessadores e nas demais esferas da cadeia produtiva. A Tabela 1 mostra a tipologia comercial de peixes proposta por Moraes (2008) e a lógica de mercado predominante entre as espécies no âmbito da área de estudo.

Tabela 1. Tipologia comercial de peixes e a lógica de mercado das espécies estudadas.

\begin{tabular}{|l|l|l|}
\hline Tipologia comercial & \multicolumn{1}{|c|}{ Espécies (estudadas) } & \multicolumn{1}{|c|}{$\begin{array}{c}\text { Lógica de } \\
\text { mercado }\end{array}$} \\
\hline $\begin{array}{l}\text { Peixes de escama } \\
\text { populares }\end{array}$ & $\begin{array}{l}\text { Jaraqui (Semaprochilodua insignis); } \\
\text { Pacu (Mylossoma spp.); } \\
\text { Curimatã (Procbilodus nigricans). }\end{array}$ & local \\
\hline $\begin{array}{l}\text { Peixes de escama } \\
\text { nobres }\end{array}$ & $\begin{array}{l}\text { Pirarucu (Arapaima gigas); } \\
\text { Tambaqui (Colossoma macropomum); } \\
\text { Matrinxã (Brycon cephalus). }\end{array}$ & regional \\
\hline Bagres & $\begin{array}{l}\text { Dourada (Brachyplatystoma flavicans); } \\
\text { Piramutaba (Brachyplatystoma vaillantti); } \\
\text { Piraíba (Brachyplatystoma filamentosum). }\end{array}$ & internacional \\
\hline
\end{tabular}

Fonte: Dados de pesquisa, 2007.

A tipologia comercial e a lógica de mercado estão ligadas por meio das relações sociais e culturais que caracterizam o mercado. $O$ fato de não haver consumo de bagres no Amazonas por um tabu alimentar, ou seja, por um fator cultural, impulsiona o mercado desses peixes para a exportação. Ao contrário, o alto consumo dos peixes de escama populares nas cidades da calha do Rio Solimões faz com que a lógica de mercado neste caso seja local, isto é, o maior consumo se dá no âmbito da cidade, quando o peixe também é estabelecido como valor de troca. A tipologia proposta não é absoluta, mas é uma forma de ilustrar a realidade para o desdobramento das compreensões. Alguns municípios têm estabelecido um comércio regional de peixes de escama populares com outros e até mesmo com Manaus. É o caso da venda do jaraqui de Tefé para Alvarães, Uarini e Fonte Boa, peixe que chega a ser exportado para Manaus em situações específicas, geralmente por alguém que dispõe de estrutura para tal.

A principal característica dos peixes de escama populares é a ampla difusão do seu consumo no âmbito regional, consequência de sua relativa abundância; entretanto, o aspecto mais marcante é o fato de que seu mercado tem base local, o que significa uma estrutura de mercado simplificada (Figura 1). Isso traz uma menor complexidade para a divisão do trabalho na pesca que, ao produzir mercadoria, não necessariamente produz capital.

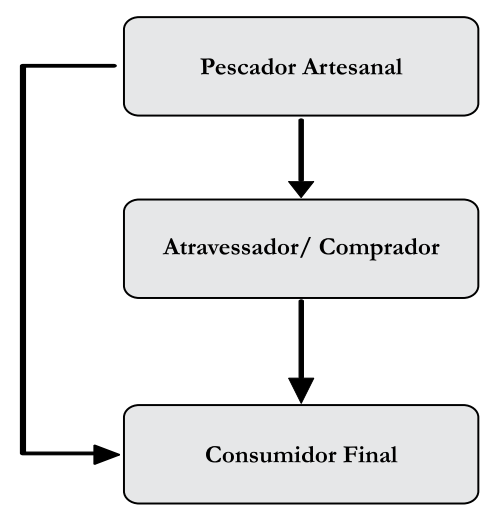

Fioura 1. Fluxograma da cadeia produtiva dos peixes de escama populares em escala local. Fonte: Dados de pesquisa, 2007.

Algumas espécies de peixes destacam-se no mercado alcançando maiores preços devido à demanda. É o caso dos peixes nobres de escamas, espécies apreciadas, principalmente em Manaus, por seu sabor e, por isso, amplamente exploradas, havendo, atualmente, um esforço para se realizar o manejo desses peixes, principalmente o do pirarucu. A estrutura de mercado que envolve essa classe é complexa em virtude das várias modalidades de pesca empregadas para as diferentes espécies (Figura 2), com Manaus detendo boa parte do mercado consumidor. 


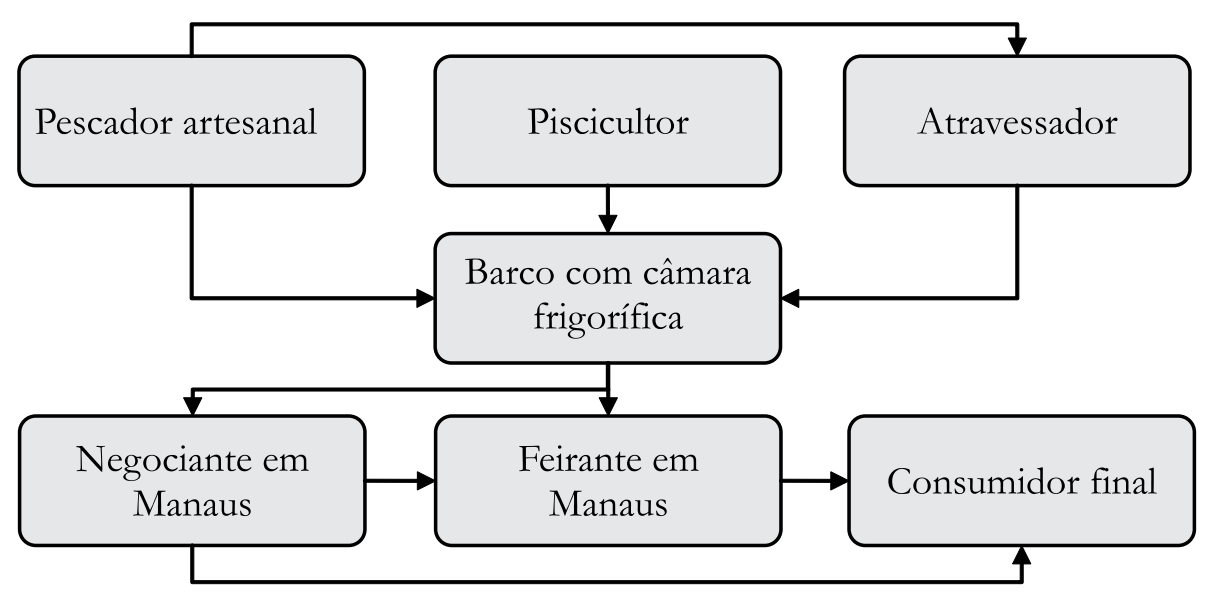

Figura 2. Fluxograma da cadeia produtiva dos peixes nobres de escamas.

Fonte: Dados de pesquisa, 2007

O mercado dos bagres possui lógica internacional para o Alto e Médio Solimões embora existam registros de mercado para esses peixes em Manaus que, entretanto, participa de outra rede que não a da exportação para Letícia. A diferenciação do mercado dos bagres leva em conta dimensões ecológicas das espécies no tocante ao ciclo de vida e questões relacionadas ao mercado e seu caráter de exportação não-local.

A cadeia produtiva dos bagres (Figura 3) conta com a participação de vários agentes que intermedeiam o processo. Entretanto, em algumas cidades como Tabatinga, a proximidade com o destino simplifica essa cadeia, permitindo que os próprios pescadores artesanais comercializem diretamente o seu pescado para as bodegas de Letícia (linha tracejada na Figura 3).

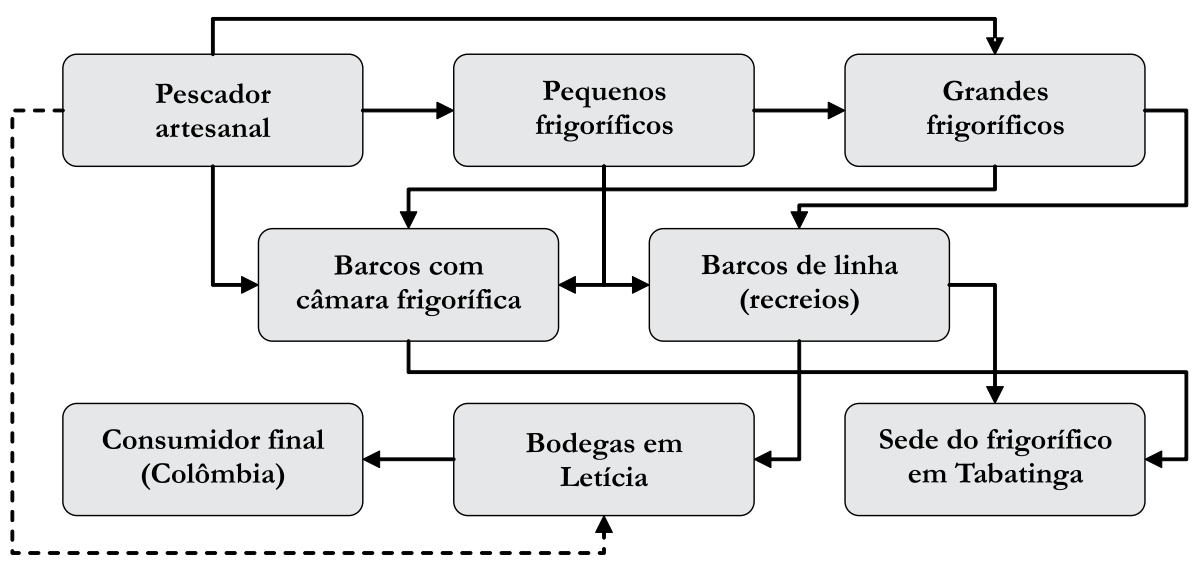

Figura 3. Fluxograma da cadeia produtiva dos bagres nas cidades estudadas. Fonte: Dados de pesquisa, 2008

\section{O TRANSPORTE DOS BAGRES E O TRABALHO}

O transporte está sujeito à condição do peixe como produto in natura, ou seja, são exigidos mecanismos de conservação das propriedades físicas do peixe sob pena de ele estragar e não poder mais ser vendido ou não mais alcançar bons preços. Esses mecanismos estão ligados ao resfriamento e/ou congelamento do pescado como forma de mantê-lo com qualidade (Figura 4). Essa circunstância também abrange dimensões de valor no sentido de que o pescador que não tem como manter o peixe conservado é obrigado a vendê-lo imediatamente, sem a possibilidade de agregar a ele mais valor em outro momento.

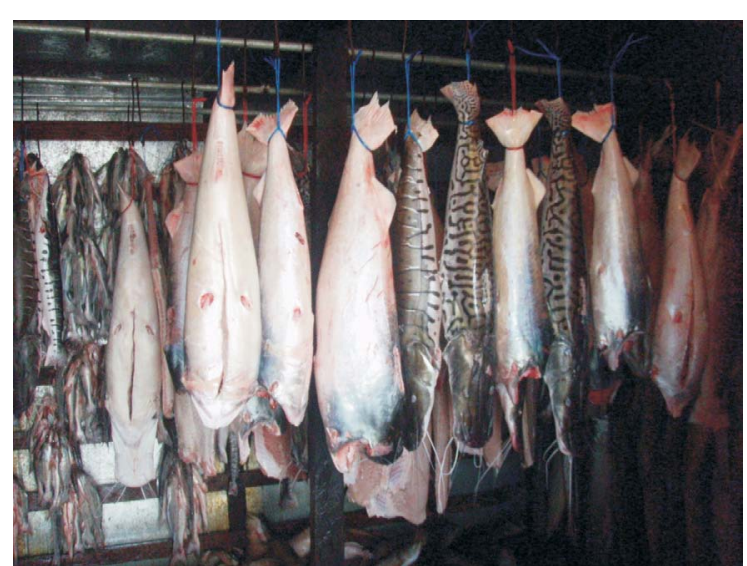

Figura 4. Armazenamento de bagres em frigorífico.

Fonte: Acervo NEPECAB (Santo Antônio do Içá, set. 2007). 
A escolha do meio utilizado para o transporte dos bagres depende da distância do local de produção ou da possibilidade de estocagem da produção até o seu destino, Letícia. A produção do entorno de Tabatinga e Benjamim Constant é transportada em canoas dos próprios pescadores ou, no caso de Benjamim Constant, os "patrões" (donos das bodegas de Letícia com os quais os pescadores têm contrato) enviam embarcações para recolher o pescado nos frigoríficos locais. Nesse caso, gastos com os insumos para o transporte (gasolina, manutenção, trabalhadores etc.) são poupados. A produção da região do Médio Solimões, concentrada em Tefé, demanda o uso de embarcações específicas com frigoríficos para o transporte do pescado, o que representa um ônus a mais no processo.

Dada essa diferenciada configuração de fluxos de transporte entre as regiões do Alto e do Médio Solimões, os dados relativos ao preço que donos de frigorífico pagam ao pescador pela compra de bagres sofrem pequenas variações. Harvey (2005) afirma que as mercadorias têm preço sensível aos custos de transporte. No mercado dos bagres, o preço pago ao pescador depende de transporte específico e das condições de mercado do transporte, consideradas não apenas a distância física, mas também a acessibilidade e a composição da rede urbana estabelecida entre as cidades que participam desse mercado. Na vazante, a dourada custava em média $\mathrm{R} \$ 5,50$ o quilo em Benjamim Constant, e R \$ 4,25 em Santo Antônio do Içá que possui menor preço que Amaturá, embora esta esteja mais próximo de Letícia.

Os pescadores de Tabatinga e Benjamim Constant alcançam melhores preços de venda de peixe por terem acesso direto ao consumidor final da estrutura considerada nesta pesquisa, as bodegas de Letícia. Existe ainda o caso dos pescadores de São Paulo de Olivença, cuja produção define a cadeia produtiva do pescado e, consequentemente, a forma de transporte: $500 \mathrm{~kg}$ de peixe. No caso de uma pescaria que renda menos de $500 \mathrm{~kg}$, os pescadores vendem o peixe aos frigoríficos locais que se encarregam de enviá-lo a Tabatinga e Letícia, o que limita a jornada de trabalho do pescador à pescaria. Quando a atividade rende mais de $500 \mathrm{~kg}$, os pescadores vendem a produção diretamente às bodegas de Letícia, com o que podem auferir maiores ganhos. Segundo relato dos pescadores, essa viagem dura 24 horas em "canoão" com motor "rabeta". Nesse caso, tem-se a jornada de trabalho do pescador aumentada, o que é justificado pelos melhores preços obtidos pelo pescado, conforme pode ser observado na Tabela 2.

A importância do transporte levou à criação de um mercado específico para esse fim. No Alto Solimões, mais especificamente em São Paulo de Olivença, há a família do Sr. Gib, que possui dois barcos com câmaras frigoríficas. Eles atuam na maior parte da calha do Solimões, direta ou indiretamente, abrangendo as cidades de Carauari, Tefé, Uarini, Alvarães, Fonte Boa, Jutaí, Tonantins, Santo Antônio do Içá e Amaturá e transportam peixes de frigoríficos que já o compraram de pescadores de outras cidades e mesmo a produção de pescadores, quando a chegada do barco coincide com o fim de uma pescaria.

$\mathrm{Na}$ vazante, quando o pescado é abundante e a logística, insuficiente para manter a estrutura de mercado dos bagres para todas as cidades, é estabelecido um sistema de cidades prioritárias (Carauari, Uarini, Fonte Boa e Tonatins) na área de atuação dessas embarcações. $\mathrm{Na}$ enchente (entressafra), os barcos passam em todas as cidades. A escolha é feita com base nos investimentos feitos nessas cidades. Os proprietários de embarcações financiam pescadores e donos de frigoríficos pequenos. Assim, a princípio, as relações não são estabelecidas por produção ou por representatividade da cidade da rede urbana da calha do rio Solimões.

Tabela 2. Tabela comparativa de preço de venda do pescador de São Paulo de Olivença diretamente para Letícia e para frigoríficos locais.

\begin{tabular}{|c|c|c|c|}
\hline \multicolumn{4}{|c|}{ Tabela de Preço do Peixe Liso } \\
\hline \multicolumn{2}{|c|}{ Espécie } & $\begin{array}{l}\text { Preço de compra } \\
\text { (Letícia) }\end{array}$ & $\begin{array}{l}\text { Preço de compra } \\
\text { (frigoríficos locais) }\end{array}$ \\
\hline \multicolumn{2}{|c|}{ Dourada } & $\mathrm{R} \$ 7,00$ & $\mathrm{R} \$ 4,90$ \\
\hline \multicolumn{2}{|l|}{ Surubim } & $\mathrm{R} \$ 6,00$ & $\mathrm{R} \$ 2,90$ \\
\hline \multirow{2}{*}{ Paraíba } & Acima de $20 \mathrm{~kg}$ & $\mathrm{R} \$ 7,00$ & $\mathrm{R} \$ 4,90$ \\
\hline & Abaixo de $20 \mathrm{~kg}$ & $\mathrm{R} \$ 5,50$ & $\mathrm{R} \$ 3,00$ \\
\hline \multicolumn{2}{|c|}{ Pacamum } & $\mathrm{R} \$ 4,00$ & $\mathrm{R} \$ 2,50$ \\
\hline \multicolumn{2}{|l|}{ Pirarara } & $\mathrm{R} \$ 2,00$ & $\mathrm{R} \$ 1,90$ \\
\hline \multicolumn{2}{|c|}{ Piramutaba } & $\mathrm{R} \$ 1,50$ & $\mathrm{R} \$ 1,00$ \\
\hline \multicolumn{2}{|l|}{ Bocão } & $\mathrm{R} \$ 1,50$ & $\mathrm{R} \$ 0,80$ \\
\hline
\end{tabular}

Fonte: Dados de pesquisa de campo, 2007.

Outras importantes funções são ainda exercidas pelas embarcações do Sr. Gib, tais como a articulação entre as cidades e a abertura de mercado para o comércio de bagres, peixes sem aceitação local por questões culturais. Além disso, os que trabalham nos barcos exercem um importante papel alfandegário, pois, na maioria dos casos, depois de embarcado o peixe, todo o processo de exportação é feito por eles, sendo que a negociação é pré-estabelecida por telefone com a bodega à qual se destinará o peixe. Não se pode esquecer que os custos do processo de exportação já estão contidos no preço do frete. 
Os navios a motor, popularmente conhecidos como barcos de recreio, são bastante utilizados no transporte de pescado, geralmente de peixes de escama populares e nobres, mas também utilizado para bagres (Figura 5). Em alguns casos, a mesma câmara frigorífica dos barcos que saem de Manaus com frango congelado e outros frios para as cidades, volta com peixes como forma de aproveitar ao máximo a viagem e o transporte.

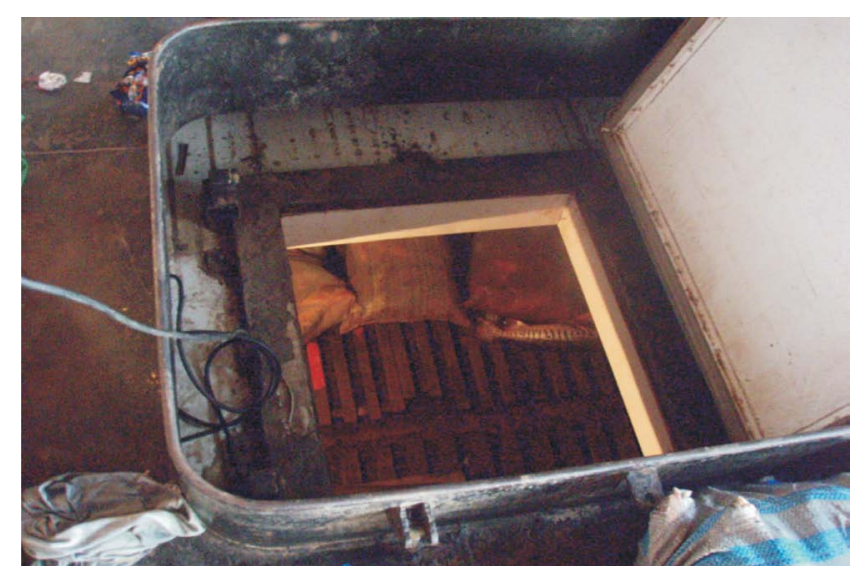

Figura 5. Transporte de pescado em câmara frigorífica de um barco de recreio com destaque para o surubim. Fonte: Acervo NEPECAB (set. 2007)

\section{O TRABALHO E AS ISCAS DO MERCADO}

A pesca geralmente está associada à atividade rural, sobretudo quando se trata do Amazonas onde, além de sua importância para a obtenção de renda (Figura 6), os ribeirinhos a consideram como uma das principais atividades de subsistência (DIEGUES, 2004). Entretanto, a realidade da pesca na calha do rio Solimões está, também, associada ao contexto urbano, pois, quando atividade rural, tem-se a cidade como lócus da comercialização da produção (CORRÊA, 2006; SINGER, 2002). Além do mais, muitos dos pescadores residem nas cidades e ali comercializam sua produção diretamente ao consumidor final ou com o intermédio dos atravessadores no âmbito do comércio local. A análise focalizará esses "pescadores urbanos", contexto em que as relações de trabalho podem ser tidas como simplificadas ou complexas de acordo com a escala adotada para a análise, pois o que se faz importante em uma escala não se manifesta na outra automaticamente (HARVEY, 2004).
Localmente, as relações de trabalho são simplificadas quando se referencia a atividade por meio da rede urbana, no que tange ao número de agentes envolvidos na estrutura de mercado e as funções que nela desempenham. Ao ampliar a escala, adequando-a aos peixes nobres de escamas e aos bagres, constata-se um maior número de agentes nesse processo agindo em níveis hierárquicos, alterando-se as relações de produção em cada um desses níveis. Essas relações trazem uma nova conotação à estrutura de mercado estabelecida. Nesse caso, as setas de orientação apresentadas na Figura 3 podem, metaforicamente, ser comparadas ao princípio matemático de "linhas" (fluxos) compostas por vários “pontos" (relações sociais).

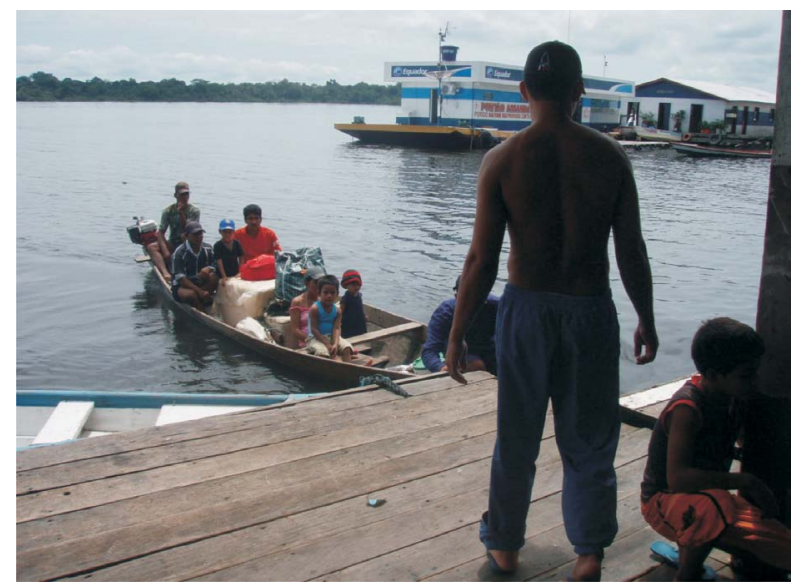

Figura 6. Família ribeirinha chegando à cidade para vender bagres. Fonte: Acervo NEPECAB (Tefé, mar. 2008).

A princípio, as relações entre o pescador, que detém os meios de produção (apetrechos de pesca) (Figura 7), e os frigoríficos, por exemplo, seriam de compra e venda de peixes. Embora isso seja uma realidade para os peixes de escama, tanto os populares quanto os nobres, na estrutura de mercado dos bagres o processo assume um caráter cíclico. Embora tenha os instrumentos básicos para a atividade pesqueira, o pescador artesanal de bagres não possui capital para trabalhar. Os donos dos frigoríficos assumem, então, o caráter de agentes financeiros, viabilizando a pescaria, pondo à disposição dos pescadores objetos de necessidade primária durante a pescaria, o gelo, o combustível e o "rancho", pagos com peixe, ou seja, no retorno da pescaria, paga-se ao(s) pescador(es) a diferença entre a produção e o valor do financiamento. No início do século XIX, na Inglaterra, praticava-se um sistema semelhante, com os proprietários de barcos de pesca financiando pescadores, sendo o rancho parte do financiamento (DIEGUES, 1983). 
O financiamento dos donos de frigoríficos também pode ser feito em espécie por causa de aspectos relacionados à família do pescador. Ao longo das cidades do Solimões, em várias ocasiões foram identificados pescadores que, para sair para a pescaria, têm que deixar uma importância em dinheiro para pagar contas ou manter a família durante a jornada de trabalho, que pode durar de dois a três dias na safra (vazante e estiagem) e até duas semanas nos períodos de entressafra (enchente e cheia) quando o pescado está escasso.

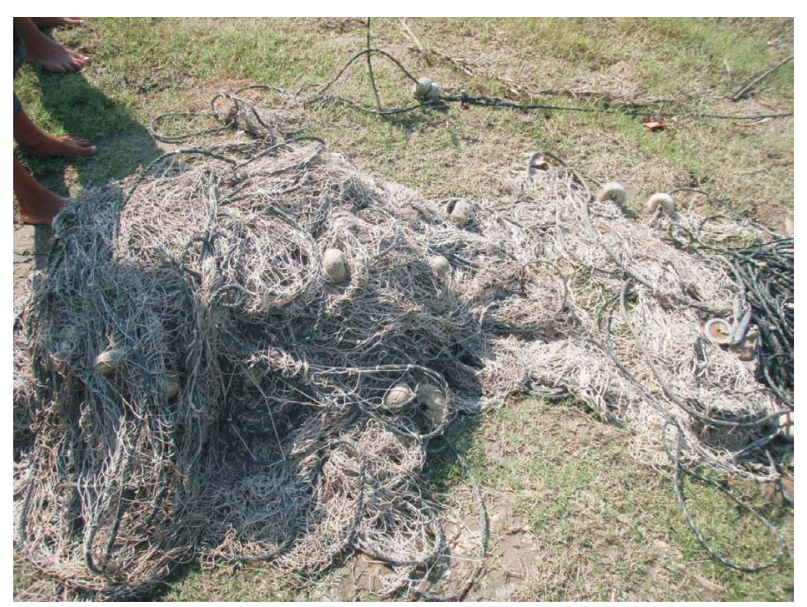

Figura 7. Pescadores preparando a rede de emalhar em São Paulo de Olivença.

Fonte: Acervo NEPECAB (set. 2007).

Mesmo no caso do financiamento em dinheiro, os pescadores das cidades mais distantes de Tabatinga não abrem mão dos objetos de primeira necessidade financiados pelos donos de frigoríficos, pois estes possuem melhores fontes para o gelo e a gasolina que têm mercados irregulares nessas cidades. As fábricas públicas de gelo têm sérios problemas e as que são relativamente bem geridas (Benjamim Constant e Santo Antônio do Içá) não atendem às demandas. Como a maioria das cidades não possui posto, a gasolina é vendida em garrafas nas ruas e nas casas (Figura 8).

Em outras etapas da cadeia produtiva, as relações podem não obedecer a uma hierarquia por outros fatores que devem ser considerados nesse processo. Tome-se como exemplo o fato de os donos de pequenos frigoríficos de Benjamim Constant terem que estabelecer relações de financiamento e ficar atentos para o preço, a fim de garantir que a produção dos pescadores lhes será vendida, pois a proximidade permitiria a venda direta em Letícia, em cadeia simplificada. Outro aspecto a considerar é o valor do financiamento, que pode ser maior, tal como ocorre em alguns casos em São Paulo de Olivença, onde os donos de frigoríficos grandes chegam a financiar motores de rabeta e apetrechos de pesca para os pescadores e donos de frigoríficos menores. É interessante notar que não foram encontrados casos em que os donos de frigoríficos também fossem donos dos meios de produção (canoa, motor, apetrechos etc.). Mesmo quando há financiamento, o objetivo é que os pescadores sejam proprietários desses bens, o que constitui uma monopolização do território pelo capital (OLIVEIRA, 2005).

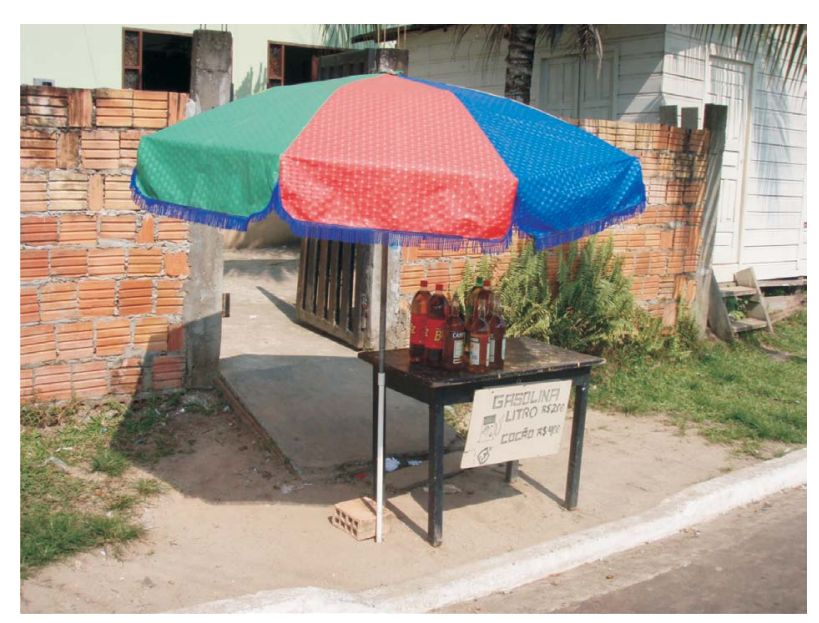

Figura 8. Forma de abastecimento de combustível no Alto Solimões (Benjamim Constant).

Fonte: Acervo NEPECAB (set. 2007).

O conceito de território na pesca, ou seja, a apropriação do espaço que passará a ter uso exclusivo, é aplicado por Cruz (2007) à territorialização das águas pelos pescadores de Manacapuru, condição também identificada no Alto Solimões. Em São Paulo de Olivença, a parte do Rio Solimões correspondente ao território municipal foi dividida em 20 partes, distribuídas a 20 grupos de associados da colônia, cada grupo atuando em uma parcela do rio. As margens de atuação foram definidas de acordo com o tipo de sedimento transportado pelas águas; assim, foram escolhidas aquelas cujos sedimentos não eram compostos por grandes volumes, como troncos de árvores, os quais poderiam danificar apetrechos de pesca, a exemplo das redes. No contexto amazônico, isso indica a influência das condições naturais sobre as relações sociais de produção, no âmbito da territorialização das áreas de uso da pesca. 
As relações de trabalho estão presentes em todas as etapas da estrutura de mercado da pesca de bagres, não apenas vertical, mas também horizontalmente, com a condição em que se encontram os funcionários dos donos de frigoríficos grandes e dos donos de barcos de transporte, cujas funções dizem respeito à manutenção do flutuante/barco e à compra dos bagres (Figura 9), sendo a venda sempre de responsabilidade do dono a quem competem as negociações.

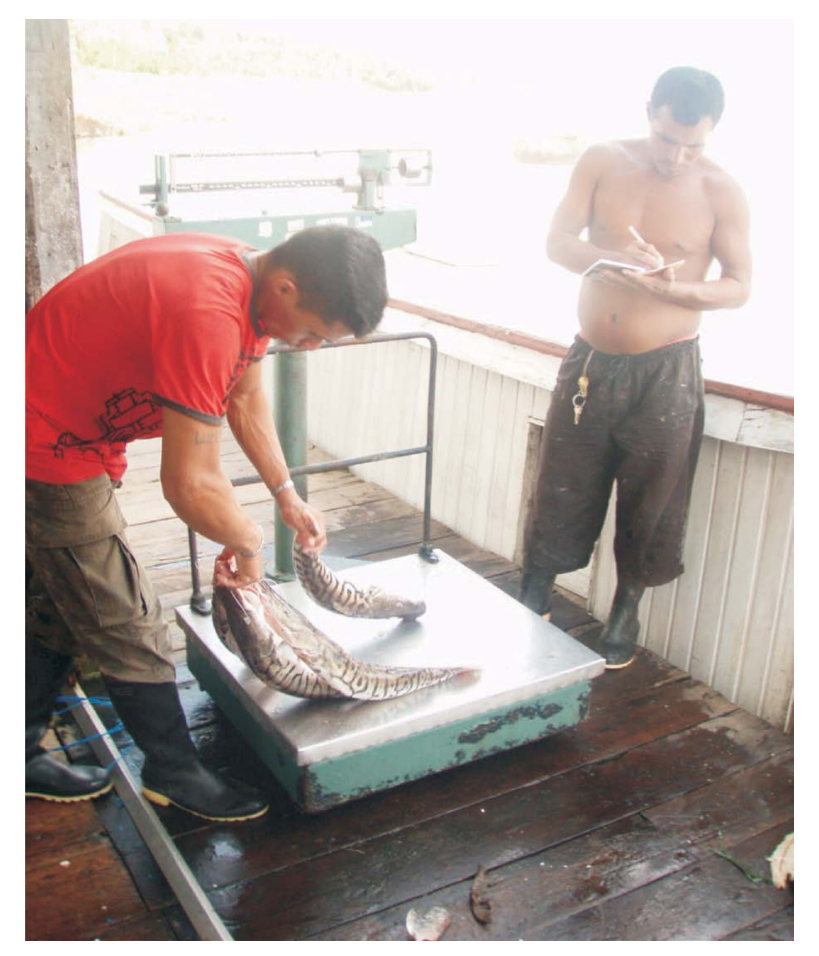

Figura 9. Funcionário de frigorífico realizando a compra de bagres. Fonte: Acervo NEPECAB (São Paulo de Olivença, set. 2007).

Presente nas relações de trabalho, a discussão sobre o peixe como mercadoria projeta pareceres sobre as relações que são estabelecidas no âmbito da captura e da comercialização. Os hábitos de pesca, entendidos como os processos socioculturais, sejam eles de mercado ou não, que constituem a atividade pesqueira são modificados por contato com o mercado. Quando passam da pesca de peixes com escama populares e nobres para a pesca de bagres, os pescadores artesanais modificam os ambientes de pesca, o tipo de apetrecho utilizado, a jornada de trabalho e outros aspectos. Com a mudança inauguram-se, ainda, as relações de financiamento supracitadas e a condição de pesca inscrita no modo capitalista de produção, tendo a produção de valor de troca como objetivo (DIEGUES, 1983).

\section{CONSIDERAÇÕES FINAIS}

A atividade pesqueira passa por um momento de transição que se caracteriza pela complexidade de novas formas de produção introduzidas num contexto específico. No caso da pesca de bagres, isso se torna mais evidente. Mesmo mantendo-se constante, no que tange à demanda no âmbito local e estadual, a pesca passa a ter novas demandas a partir do mercado internacional, que rearranjam o espaço produtivo e estabelecem novas relações que, ainda em processo, são determinantes para essas estruturas de mercado e rede de comercialização e, consequentemente, para os agentes que delas participam.

A adequação desse mercado internacional às condições amazônicas resulta em novas configurações que redimensionam o modo de vida do pescador e, adaptando-se à falta de infraestrutura e serviços locais (abastecimento de gasolina e gelo, principalmente) para sustentar a atividade, potencializam outras formas de relação entre agentes da cadeia produtiva.

A inexistência de arranjos produtivos locais que beneficiariam os bagres, aliada à alta perecibilidade do peixe, condiciona as relações de trabalho ao imediatismo, afetando o pescador que, por não ter opção de armazenamento, está fadado a se sujeitar às condições impostas pelos donos de frigoríficos. Este, por sua vez, também se sujeita às bodegas de Letícia, que dão o tom dessa transição e, a partir da capacidade de absorverem toda a produção do Solimões, assumem um papel decisivo nesse processo. Daí a necessidade de reflexão sobre as relações de trabalho, que se modificam e assumem novas configurações nesse contexto, redesenhando o mercado e determinando cada vez mais o modo de vida dos pescadores.

\section{REFERÊNCIAS}

ABRAMOVAY, R. Entre Deus e o diabo: mercado e interações humanas nas ciências sociais. Disponível em: <http://www.econ.fea.usp.br/abramovay/>. Acesso em: 23 jan. 2008.

BARTHEM, R. B.; GOULDING, M. Os bagres balizadores: ecologia, migração e conservação de peixes amazônicos. Tefé: Sociedade Civil Mamirauá; Brasília: CNPq, 1997. 
BATISTA, J. S. Estimativa da variabilidade genética intra-específica da dourada - Brachyplatystoma flavicans Castelnau 1855 (Pimelodidae - Siluriformes) no Sistema Estuário- Amazonas-Solimões. 2001. 113f. Dissertação (Mestrado em Biologia de Água Doce e Pesca Interior) - Instituto Nacional de Pesquisas da Amazônia - INPA, Manaus, 2001.

CORRÊA, R. L. Estudos Sobre a Rede Urbana. Rio de Janeiro: Bertrand Brasil, 2006.

CRUZ, M. J. M. Rios e Lagos: apropriação da pesca pelos camponeses-ribeirinhos na Amazônia. In: BRAGA, S. I. G. (Org.). Cultura popular, patrimônio material e cidades. Manaus: EDUA, 2007.

DIEGUES, A. C. S. A pesca constituindo sociedades. São Paulo: NUPAUB/ USP, 2004.

DIEGUES, A. C. S. Pescadores, camponeses e trabalhadores do mar. São Paulo: Ática, 1983. (Ensaios 94).

HARVEY, D. A produção capitalista do espaço. Tradução de Carlos Szlak. São Paulo: Annablume, 2005. (Coleção Geografia e Adjacências).

HARVEY, D. Espaços de Esperança. Tradução de Adail Ubirajara Sobral e Maria Stela Gonçalves. São Paulo: Loyola, 2004.

MARX, K. O capital: crítica da economia política. Tradução de Regis Barbosa e Flávio R. Kothe. 2 ed. São Paulo: Nova Cultural, 1985. (Os Economistas).

MORAES, A. O. Caiu na rede, é peixe: um estudo sobre a rede urbana da calha do Rio Solimões a partir do mercado de peixes em Tabatinga, Tefé e Manaus. Manaus: UFAM, 2008, 59 p. (Relatório Final de Programa Institucional de Bolsas de Iniciação Científica - PIBIC).

OLIVEIRA, A. U. A Geografia agrária e as transformações atuais no campo brasileiro. In: CARLOS, A. F. A. (Org.). Novos caminhos da Geografia. São Paulo: Contexto, 2005. (Caminhos da Geografia).

SINGER, P. Economia política da urbanização. São Paulo: Contexto, 2002.

WELCOMME, R. Prefácio. In: ALMEIDA, O T. (Org.). Manejo de pesca na Amazônia brasileira. São Paulo: Peirópolis, 2006. 